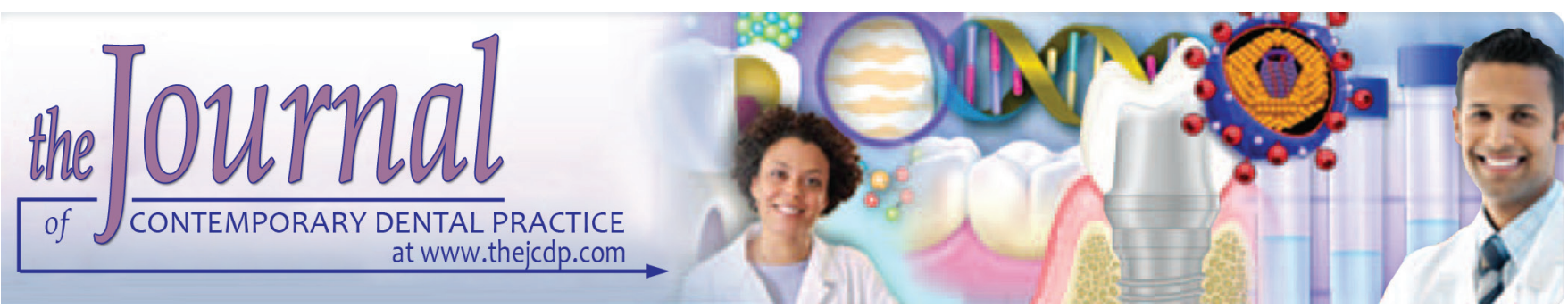

\title{
Evaluation of Root Fracture in endodontically treated Teeth using Cone Beam Computed Tomography
}

\author{
${ }^{1}$ Mariana Tiepo, ${ }^{2}$ Gabriel Magrin, ${ }^{3}$ Ana C Kovalik, ${ }^{4}$ Belkiss Marmora, ${ }^{5}$ Milena F Silva, ${ }^{6}$ Ricardo Raitz
}

\begin{abstract}
Aim: Our objective was to perform an in vitro evaluation of root fracture in endodontically treated teeth using two cone beam computed tomography (CBCT) machines.
\end{abstract}

Materials and methods: The sample comprised 86 singlerooted human premolars that had been fractured by a universal testing machine. The tomographic images were acquired using an Orthopantomograph OP $300^{\circledR}$ and an Orthophos XG $3 D^{\circledR}$ and evaluated by three examiners, by means of specific software. The teeth were classified into presence or absence of root fracture, then the root third where the fracture occurred, was determined. With regard to the detection of the fracture, the Kappa statistic was used for intra and interexaminer reproducibility at two distinct points in time. Chi-squared test was employed to analyze the sensitivity and specificity of the two tomographs $(p<0.05)$.

Results: The results showed a good or excellent Kappa index between examiners. As for the absolute frequency, the sensitivity (0.6) of the Orthophos XG 3D ${ }^{\circledR}$ equipment was superior, while specificity (0.91) was higher with the Orthopantomograph OP $300^{\circledR}$. On the receiver operating characteristics curve, moderate performance was found with an accuracy of 0.73 (OrthopantomographOP $300^{\circledR}$ ) and 0.74 (Orthophos XG 3D ${ }^{\circledR}$ ) respectively. As far as the location of the root fracture is concerned, moderate agreement was verified using the Kappa statistic $(k=0.56)$.

\footnotetext{
${ }^{1}$ Department of Oral Pathology, Oral Diagnosis and Oral Radiology, São Leopoldo Mandic Research Center, Campinas São Paulo, Brazil

${ }^{2,5,6}$ Department of Oral Radiology, São Leopoldo Mandic Research Center, Campinas, São Paulo, Brazil

${ }^{3}$ Department of Oral Implantology, Federal University of Santa Catarina, Florianópolis, Santa Catarina, Brazil

${ }^{4}$ Department of Periodontology, Regional University of Blumenau, Blumenau, Santa Catarina, Brazil

Corresponding Author: Ricardo Raitz, Department of Oral Pathology, Oral Diagnosis and Oral Radiology, São Leopoldo Mandic Research Center, Campinas, São Paulo, Brazil, e-mail: ricardoraitz@ig.com.br
}

Conclusion: Although the regular CBCTs represent the imaging examination of choice for assisting root fracture diagnosis in endodontically treated teeth, their performance in this study demonstrated an imprecise diagnosis of fractures in a good many cases, irrespective of the tomography machine used.

Clinical significance: An early and precise detection of root fractures is of the utmost clinical importance, but the radiopaque and/or metallic filling materials in the CBCT viewing field may generate artifacts, known as the beam-hardening effect, which could compromise root fracture detection.

Keywords: Cone beam computed tomography, Diagnosis, Root fracture.

How to cite this article: Tiepo M, Magrin G, Kovalik AC, Marmora B, Silva MF, Raitz R. Evaluation of Root Fracture in endodontically treated Teeth using Cone Beam Computed Tomography. J Contemp Dent Pract 2017;18(2):94-99.

\section{Source of support: Nil}

Conflict of interest: None

\section{INTRODUCTION}

Endodontic treatment performed on the root canal system may cause weakening of the remaining dental structure due to the removal of dentin caused by the stages of access and modeling of the root canal. Moreover, the filling of the canal is performed using materials, such as gutta-percha cones and metal posts that have differences in modulus of elasticity in relation to the tooth remainder. ${ }^{1-3}$ In addition, the reduction in the receptor functions of the pulp and periodontal ligament increases susceptibility to the occurrence of root fractures during the application of occlusal forces. ${ }^{3,4}$

Depending on extension, location, and time until diagnosis, root fractures may be adequately treated or could adversely affect the permanence of the tooth. As a consequence of the fracture, alveolar bone resorption and degeneration of periodontal ligament fibers and dental pulp structures may occur. ${ }^{5}$ Therefore, an early diagnosis 
that includes a complete assessment of the case history and a detailed clinical examination is very important for the prognosis of the treatment.

Periapical radiography is still the first method for obtaining an image in cases of suspected root fracture, as it is possible to view subtle alterations in the periodontal ligament space, periapical lesions, and bone resorption. ${ }^{6}$ These radiographic images, however, are limited when it comes to detecting fractures, particularly vertical fractures, as the line of fracture can only be viewed when it is directly aligned with the X-ray beams, which is not true for the majority of cases. Moreover, the anatomical structures overlapping considerably reduce the examination's sensitivity as it is a two-dimensional (2D) image of three-dimensional (3D) structures. ${ }^{7,8}$

Cone beam computed tomography (CBCT) permits an analysis of the fractures in a variety of $3 \mathrm{D}$ cross-sections and different angles, thereby, eliminating the superimposition of images that occurs in periapical radiography. ${ }^{9-11}$ It also allows classification in terms of direction (horizontal, vertical, or oblique) and fracture location (apical, middle, or cervical third of the root). ${ }^{12}$ Nevertheless, it can be seen that in the majority of cases of fracture, the tooth has received endodontic treatment and the insertion of intraradicular posts. These radiopaque and/or metallic filling materials in the CBCT viewing field may generate artifacts in the form of striations or streaks, known as the beam-hardening effect, which could compromise root fracture detection in terms of the sensitivity and specificity of the diagnosis. ${ }^{13,14}$

Considering that an early and precise detection of root fractures is of the utmost clinical importance, the aim of this study is to perform an in vitro analysis of root fracture diagnosis in endodontically treated teeth, using two different CBCT machines.

\section{MATERIALS AND METHODS}

\section{Preparation of Samples}

The sample comprised 86 single-rooted human premolars that went through three analytical stages prior to being accepted into the study: Visual inspection, evaluation through a stereoscopic magnifier (Tecnival SQF-F ${ }^{\circledR}$; Curitiba, Paraná, Brazil), and checking through digital periapical radiography (Timex $70 \mathrm{E}$, Gnatus ${ }^{\circledR}$, Ribeirão Preto, São Paulo, Brazil). Only teeth that had at least two preserved crown surfaces were included in the study. Teeth with incomplete root formation, intraradicular posts, prior endodontic manipulation, presence of tooth resorption, calcified root canals, or multi-rooted teeth were rejected from the study. Also discarded from the study were teeth with cracks and root fractures at the stage of sample selection.
The selected teeth were sanitized using distilled water and disinfected with $70 \%$ alcohol. Then, with the aid of a Gracey type no. 13/14 periodontal curette (Hu-Friedy ${ }^{\circledR}$, Chicago, IL, USA), the remnants of periodontal ligament adhered to the dental structure were scraped away. All the teeth were endodontically treated using the crowndown technique, with patency and widening of the apical foramen, and filled using the technique of lateral condensation of gutta-percha cones (Dentsply ${ }^{\circledR}$ DeTreyGmbH, Konstanz, Germany) with endodontic cement (AHPlus, Dentsply ${ }^{\circledR}$ DeTrey $\mathrm{GmbH}$ ). The teeth were then packed in plastic containers and kept hydrated in distilled water awaiting the performance of the root fractures.

After concluding the endodontic treatment, the teeth were numbered and divided randomly into two groups, one group being subjected to fracture $(n=43)$ and the other maintained as the control $(n=43)$. The experimental group samples were coated with a thin layer of no. 7 red wax (DentBras ${ }^{\circledR}$, Pirassununga, São Paulo, Brazil) as far as the cervical region (enamel-cementum junction) to simulate the periodontal ligament and inserted in polyvinyl chloride tubes (Tigre S/A Tubos e Conexões ${ }^{\circledR}$, Rio Claro, São Paulo, Brazil) with a self-curing acrylic resin (Jet ${ }^{\circledR}$, Artigos Odontológicos Clássico Ltda., Campo Limpo Paulista, São Paulo, Brazil).

\section{Root Fracture Induction}

The specimens from the experimental group were subjected to fracture in a universal testing machine $\left(\mathrm{EMIC}^{\circledR}\right.$ DL 2000; São José dos Pinhais, Paraná, Brazil) with a compression load at a speed of $1 \mathrm{~mm} /$ minute, by means of an active tip fabricated with a nickel-plated steel industrial sewing-machine needle, specially developed for this study. This metal tip was introduced into the entry of the root canal causing a fracture, which was determined by the characteristic noise of fracture or by the automatic stop of the machine, programed to stop applying force when there is no longer any resistance.

All the fractured teeth were inspected once again with the aim of confirming whether the induction of the root fracture was successful and to determine the location of the fracture, in the cervical, middle, or apical third. This reassessment (gold standard) took place by direct visual analysis, followed by the use of an Optilux ${ }^{\circledR} 501$ curing light (Demetron, Kerr-Sybron Dental, Orange, CA, USA) and completed through observation with a stereoscopic magnifier (Tecnival SQF-F ${ }^{\circledR}$ ).

\section{Tomographic Analysis}

For the acquisition of standardized tomographic images, all the teeth from both groups were placed on a wax support (ASFER-Indústria Química Ltda. ${ }^{\circledR}$, São Caetano 
do Sul, São Paulo, Brazil) inside a container filled with water to simulate the attenuation of radiation through the soft tissue. ${ }^{15-17}$ The scans were performed using the OrthopantomographOP300 ${ }^{\circledR}$ (Instrumentarium Dental, Charlotte, NC, USA) tomograph with a protocol of $0.2 \mathrm{~mm}$ voxels, field of view (FOV) of $6 \times 8 \mathrm{~cm}$, acquisition time of 6.1 seconds, at $90 \mathrm{kV}$ and $10 \mathrm{~mA}$, and the Orthophos XG 3D ${ }^{\circledR}$ (Sirona, Bensheim, Germany) tomograph with a protocol of $0.16 \mathrm{~mm}$ voxels, FOV of $8 \times 8 \mathrm{~cm}$, acquisition time of 14.4 seconds (high resolution), at $85 \mathrm{kV}$, and $10 \mathrm{~mA}$.

The interpretation of the images was carried out by three specialist examiners (two oral radiologists and an endodontist) with at least 3 years' experience in their specialties. All the examiners were trained in the use of OnDemand3D Dental (OrthopantomographOP300 ${ }^{\circledR}$ ) (Fig. 1) and Galileos (Orthophos XG 3D ${ }^{\circledR}$ ) (Fig. 2) viewing software. During the image analysis, the examiners were able to use all the available program resources (different reconstruction plans, zoom, brilliance, contrast, and filters) with no time limit. Using a table, the examiners recorded their reports of presence or absence of fracture ${ }^{8,10,18-20}$ and, in positive cases of fracture, the location of the fracture was determined (cervical, middle, or apical third).

\section{Statistical Analysis}

Using Kappa statistic, intra- and interexaminer reproducibility (agreement) was checked at two distinct moments for the detection of root fractures in the total sample ( $n=86)$. The images obtained were checked against the true diagnosis (gold standard) using the following indicators: Sensitivity, specificity, false-negative error rate, falsepositive error rate, predictive positive value, and predictive negative value. The accuracy of the images obtained using both tomographs was calculated through the area under the receiver operating characteristics (ROC) curve.

Chi-squared test was applied to analyze the sensitivity and specificity of the two tomographs in the detection of root fractures in endodontically treated teeth. To perform the statistical calculations, the software Statistical Package for the Social Sciences version $20^{\circledR}$ (Inc., Chicago, Illinois, USA) was employed, considering a level of significance of $95 \%(p=0.05)$.

\section{RESULTS}

Kappa statistic used to evaluate the agreement of the responses of each of the three examiners, at the two moments of image evaluation, ranged from 0.39 to 0.65 . Reproducibility between examiners was either good or excellent, with Kappa indices ranging from 0.70 to 0.81 . Therefore, to proceed with the calculations, the data of only one of the examiners were considered. By comparing the location of the fractures observed against the true diagnosis (gold standard), Kappa statistic demonstrated moderate agreement in terms of the root third where fractures were found, with an index of 0.56 .

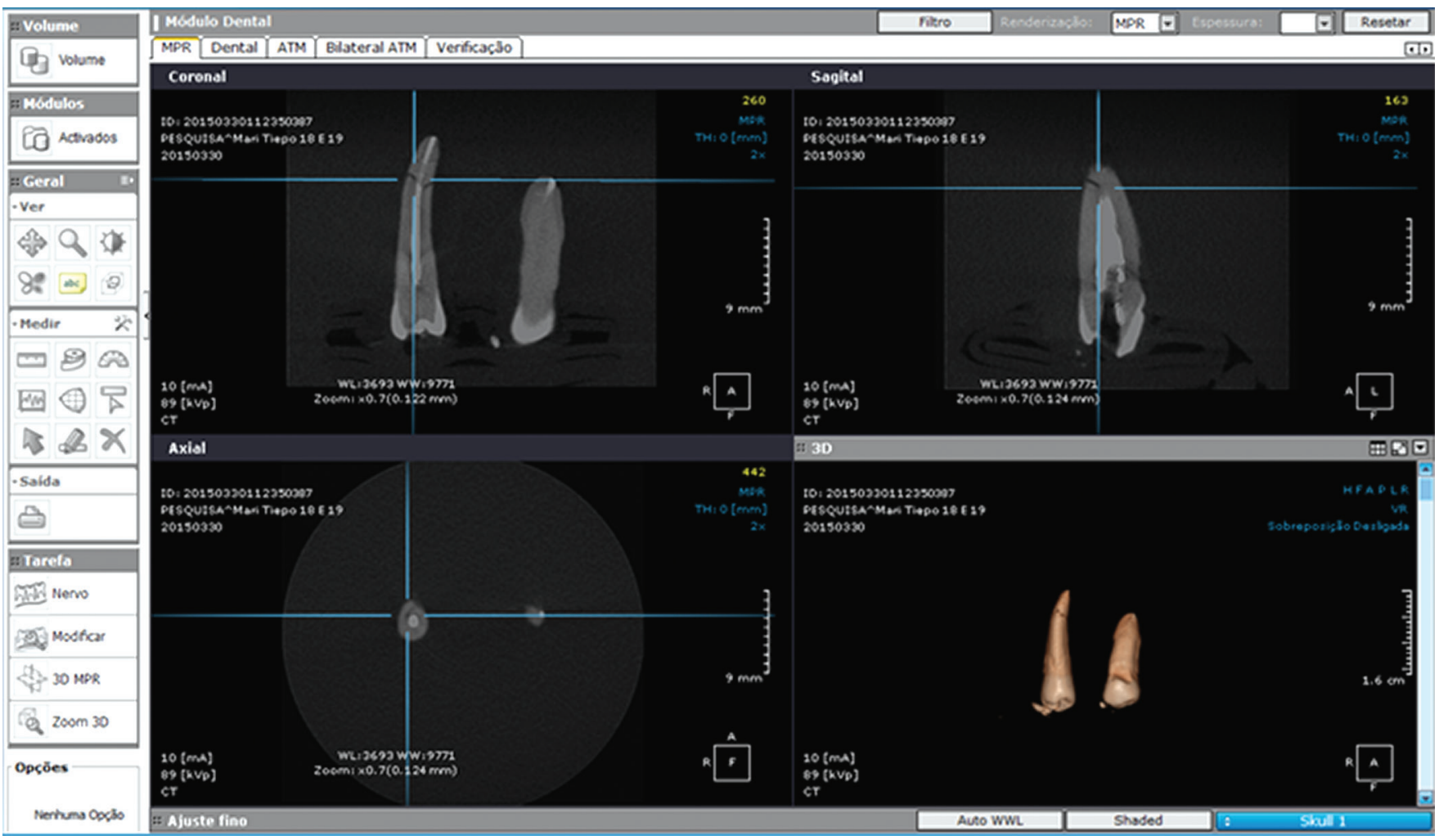

Fig. 1: OnDemand3D Dental (OrthopantomographOP300 ${ }^{\circledR}$ ) viewing software 


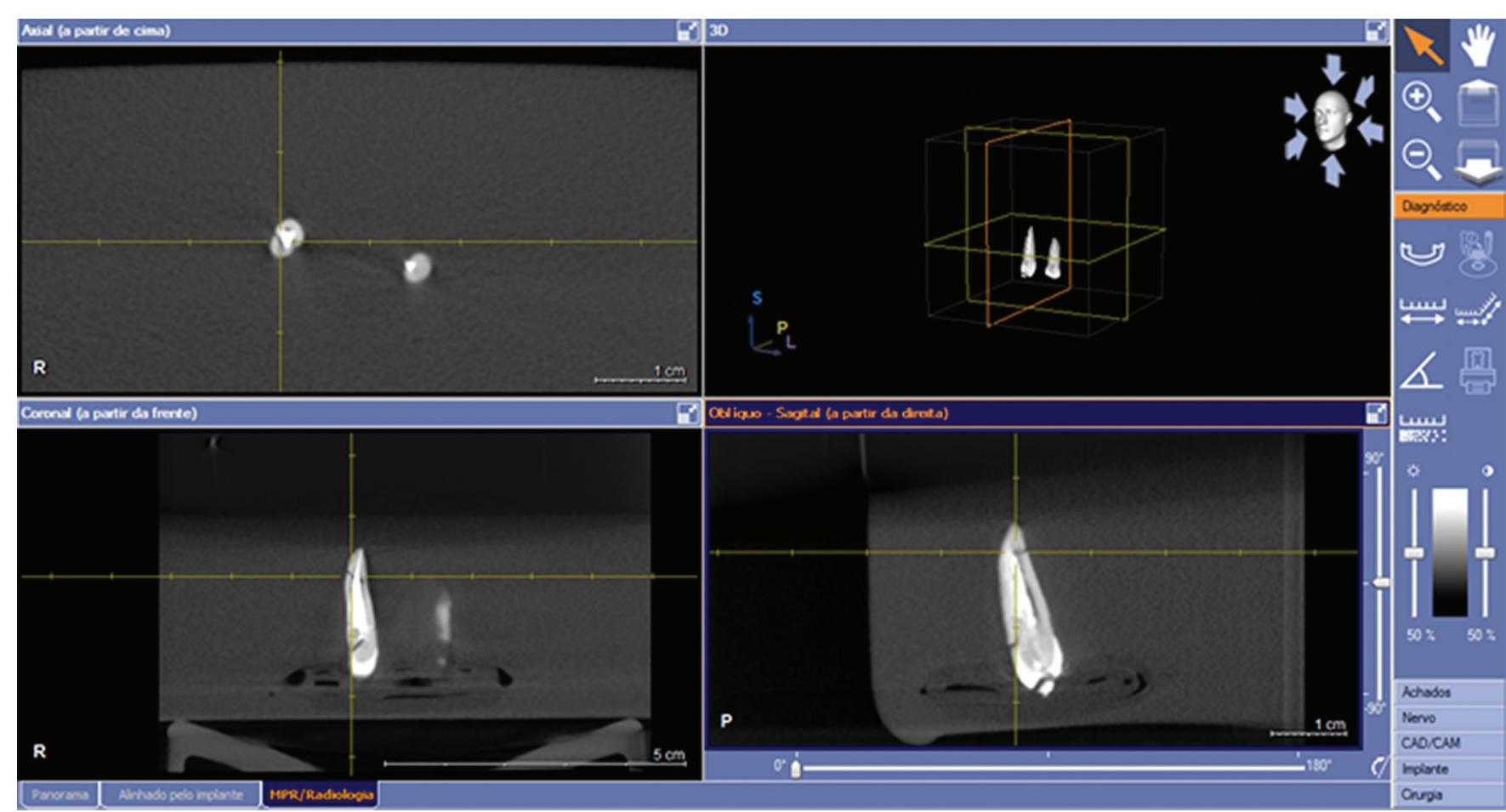

Fig. 2: Galileos (Orthophos XG 3D ${ }^{\circledR}$ ) viewing software

Table 1: Absolute frequency of root fractures in endodontically treated teeth by tomograph vs the true diagnosis

\begin{tabular}{|c|c|c|c|}
\hline \multirow{2}{*}{$\begin{array}{l}\text { Orthopantomograph } \\
\text { OP } 300^{\circledR}\end{array}$} & \multicolumn{2}{|c|}{ True diagnosis } & \multirow[b]{2}{*}{ Total } \\
\hline & Fracture present & No fracture & \\
\hline Fracture present & 24 & 4 & 28 \\
\hline No fracture & 19 & 39 & 58 \\
\hline \multirow[t]{2}{*}{ Total } & 43 & 43 & 86 \\
\hline & \multicolumn{2}{|c|}{ True diagnosis } & \\
\hline Orthophos XG 3D® & Fracture present & No fracture & Total \\
\hline Fracture present & 26 & 5 & 31 \\
\hline No fracture & 17 & 38 & 55 \\
\hline Total & 43 & 43 & 86 \\
\hline
\end{tabular}

Depending on the absolute frequency in which root fractures were detected in the images obtained vs the true diagnosis, it was possible to see that the sensitivity of the Orthophos XG 3D ${ }^{\circledR}$ was greater (Table 1). As far as specificity is concerned, the Orthopantomograph OP $300^{\circledR}$ was found to be better. The use of this equipment also contributed to the images demonstrating a greater positive predictive value. On the other hand, higher negative predictive values were found when using the Orthophos XG 3D ${ }^{\circledR}$ tomograph (Table 2).

From the ROC curve (Graph 1), it was possible to verify that root fracture diagnosis in endodontically treated teeth exhibited an accuracy of 0.73 and 0.74 respectively, for the Orthopantomograph OP $300^{\circledR}$ and Orthophos XG $3 \mathrm{D}^{\circledR}$ tomographs, which was considered moderate.

Using Chi-squared test, it was found that the number of fracture diagnoses through CBCT was significantly
Table 2: Indicators of validity of tomographic images obtained from two separate machines for the diagnosis of the presence and absence of root fractures in endodontically treated teeth

\begin{tabular}{lll}
\hline Validity measurement & $\begin{array}{l}\text { Orthopantomograph } \\
\text { OP300 }\end{array}$ & $\begin{array}{l}\text { Orthophos } \\
X G 3 D^{\circledR}\end{array}$ \\
\hline Sensitivity & 0.56 & 0.60 \\
Specificity & 0.91 & 0.88 \\
False-negative error rate & 0.44 & 0.40 \\
False-positive error rate & 0.09 & 0.12 \\
Positive predictive value & 0.86 & 0.84 \\
Negative predictive value & 0.67 & 0.69 \\
\hline
\end{tabular}

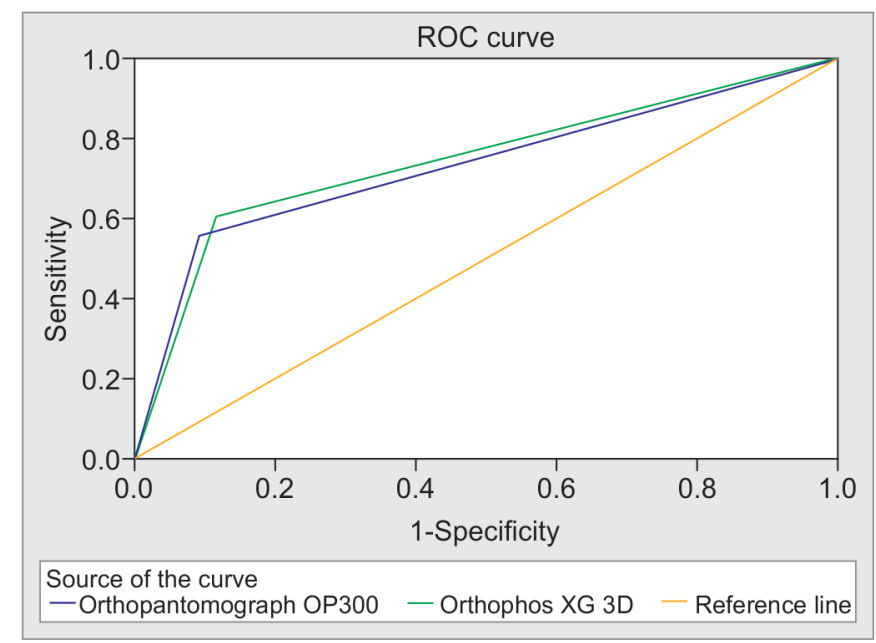

Graph 1: Receiver operating characteristics curve showing the accuracy of the tomographs evaluated in the diagnosis of root fractures in endodontically treated teeth 
Table 3: Absolute $(n)$ and relative (\%) frequencies of the presence and absence of root fractures in endodontically treated teeth, by type of examination

\begin{tabular}{lll}
\hline & \multicolumn{2}{c}{ Incomplete root fracture } \\
\cline { 2 - 3 } Examination type & Present (\%) & Absent (\%) \\
\hline True diagnosis & $43(50.0)$ & $43(50.0)$ \\
Orthopantomograph OP300 & $28(32.6)$ & $58(67.4)$ \\
Orthophos XG 3D & $31(36.0)$ & $55(64.0)$ \\
Chi-squared test & $\mathrm{p}=0.047$ & \\
\hline
\end{tabular}

lower when compared with the true diagnosis $(\mathrm{p}=0.047)$. There was, however, no statistical difference between the Orthopantomograph OP300 ${ }^{\circledR}$ and Orthophos XG 3D ${ }^{\circledR}$ tomographs (Table 3).

\section{DISCUSSION}

The diagnosis of root fracture in endodontically treated teeth is a challenge faced by clinicians. The literature points out that 2D examinations, such as periapical radiographs have a low capacity to detect these fractures, and thus 3D examinations, such as CBCT have gained more prominence. ${ }^{7,8,19,21}$ However, even with CBCT, visualizing the fracture line is difficult and a variety of factors influence the diagnosis.

Iikubo et $\mathrm{al}^{22}$ in a study performed with dogs obtained significant results for CBCT efficiency in the diagnosis of root fracture, with a sensitivity of 0.6 , specificity of 0.91 , positive predictive value of 0.90 , and a negative predictive value of 0.96 . They concluded that this type of examination was the most reliable among the image acquisition modes studied (i.e., conventional intraoral radiography, helical computed tomography, and CBCT).

In the present study, whose sample comprises teeth endodontically treated with gutta-percha, it was found that $\mathrm{CBCT}$ had the following ranges of variation: Sensitivity (0.56-0.60), specificity (0.88-0.91), positive predictive value (0.84-0.86), and negative predictive value (0.67-0.69). Using the ROC curve, the fracture diagnosis showed an accuracy of 0.73 and 0.74 with the Orthopantomograph OP $300^{\circledR}$ and Orthophos XG $3 \mathrm{D}^{\circledR}$ tomographs respectively, demonstrating that both examinations performed moderately. Other studies demonstrate more satisfactory results, such as the study by Hassan et $\mathrm{al}^{,}{ }^{8}$ which confirmed good performance (0.86), and likubo et $\mathrm{al}^{22}$ with an accuracy rated as excellent (0.93). As far as the present study is concerned, the CBCT examination may be considered as just a complementary examination for diagnosis and indication of treatment planning when the existence of a dental root fracture is clinically suspected. Fracture diagnosis, i.e., heavily CBCT based should be treated with extreme caution as the accuracy was found to be moderate and a wrong diagnosis could lead the clinician to perform unnecessary invasive treatments or maintain fractured teeth wrongly diagnosed, which could cause periodontal bone loss. Root fracture diagnosis techniques for endodontically treated teeth still need to be improved.

It should be highlighted that the variation in the results between studies may be influenced by specific characteristics of the tomographs employed. Metska et al, ${ }^{23}$ demonstrated favorable values for the Accuitomo 3D ${ }^{\circledR}$ (J. Morita, Kyoto, Japan) in detecting vertical root fractures when compared with the NewTom 3G ${ }^{\circledR}$ (Quantitative Radiology, Verona, Italy). In the present study, there was no statistically significant difference between the two devices evaluated (OrthopantomographOP300 ${ }^{\circledR}$ and Orthophos XG 3D $\left.{ }^{\circledR}\right)$, corroborating the studies of Kamburoglu et al. ${ }^{24}$ Thus, the influence of different CBCT machines on diagnostic precision, in terms of root fracture detection, is still a question of some debate. The separation of fragments is a facilitating factor in root fracture diagnosis; the smaller the space between fragments, the lower is the capacity for detection. Different techniques for obtaining the fracture could also explain the different results. In this and other studies, a universal testing machine was used, as it provides discrete root fractures and can, therefore, simulate incipient cases of fracture in patients. ${ }^{25}$

Despite the fact that the CBCT is treated as the best complementary examination available for detecting root fractures, a caveat should be taken into consideration due to the presence of filling materials inside the root canal. Several studies have shown that possible variations in the results can be influenced by artifacts in the images obtained by CBCT, such as gutta-percha, endodontic cements, and metal cores. ${ }^{8,18,21}$

It can be concluded that the diagnosis of root fractures in endodontically treated teeth is not adequate using CBCT alone, regardless of the type of tomographic apparatus employed. Nevertheless, CBCT represents a powerful tool to help in the diagnosis of root fractures. The performance of new tomographs for the early assessment of root fractures and the improvement in software resources to reduce the effect of artifacts in images are important topics that require further investigation.

\section{REFERENCES}

1. Akkayan B, Gülmez T. Resistance to fracture of endodontically treated teeth restored with different post systems. J Prosthet Dent 2002 Apr;87(4):431-437.

2. Cotton TP, Geisler TM, Holden DT, Schwartz SA, Schindler WG. Endodontic applications of cone-beam volumetric tomography. J Endod 2007 Sep;33(9):1121-1132.

3. Schwarz S, Lohbauer U, Petschelt A, Pelka M. Vertical root fractures in crowned teeth: a report of 32 cases. Quintessence Int 2012 Jan;43(1):37-43.

4. Montandon A, Zuza E, Toledo BE. Prevalence and reasons for tooth loss in a sample from a dental clinic in Brazil. Int J Dent 2012;2012:719750. 
5. Peciuliene V, Rimkuviene J. Vertical root fractures in endodontically treated teeth: A clinical survey. Stomatologija 2004;6(3):77-80.

6. Ellis SG. Incomplete tooth fracture - proposal for a new definition. Br Dent J 2001 Apr;190(8):424-428.

7. Bernardes RA, deMoraes IG,Húngaro DuarteMA,AzevedoBC, de Azevedo JR, Bramante CM. Use of cone-beam volumetric tomography in the diagnosis of root fractures. Oral Surg Oral Med Oral Pathol Oral Radiol Endod 2009 Aug;108(2): 270-277.

8. Hassan B, Metska ME, Ozok AR, van der Stelt P, Wesselink PR. Detection of vertical root fractures in endodontically treated teeth by a cone beam computed tomography scan. J Endod 2009 May;35(5):719-722.

9. Kositbowornchai S, Sikram S, Nuansakul R, Thinkhamrop B. Root fracture detection on digital images: Effect of the zoom function. Dent Traumatol 2003 Jun;19(3):154-159.

10. Patel S, Dawood A, Ford TP, Whaites E. The potential applications of cone beam computed tomography in the management of endodontic problems. Int Endod J 2007 Oct;40(10): 818-830.

11. Tyndall DA, Kohltfarber H. Application of cone beam volumetric tomography in endodontics. Aust Dent J 2012 Mar;57 (Suppl 1):72-81.

12. Hannig C, Dullin C, Hülsmann M, Heidrich G. Threedimensional, non-destructive visualization of vertical root fractures using flat panel volume detector computer tomography: an ex vivo in vitro case report. Int Endod J 2005 Dec;38(12): 904-913.

13. Scarfe WC, Farman AG, Sukovic P. Clinical applications of cone-beam computed tomography in dental practice. J Can Dent Assoc 2006 Feb;72(1):75-80.

14. Perrella A, Lopes PM, Rocha RG, Fenyo-Pereira M, Cavalcanti MG. Influence of dental metallic artifact from multislice CT in the assessment of simulated mandibular lesions. J Appl Oral Sci 2010 Mar-Apr;18(2):149-154.

15. Lascala CA, Panella J, Marques MM. Analysis of the accuracy of linear measurements obtained by cone beam computed tomography (CBCT-NewTom). Dentomaxillofac Radiol 2004 Sep;33(5):291-294.
16. Lagravère MO, Carey J, Toogood RW, Major PW. Threedimensional accuracy of measurements made with software on cone-beam computed tomography images. Am J Orthod Dentofacial Orthop 2008 Jul;134(1):112-116.

17. Moreira CR, Sales MA, Lopes PM, Cavalcanti MG. Assessment of linear and angular measurements on three-dimensional cone-beam computed tomographic images. Oral Surg Oral Med Oral Pathol Oral Radiol Endod 2009 Sep;108(3):430-436.

18. Hassan B, Metska ME, Ozok AR, van der Stelt P, Wesselink PR. Comparison of five cone beam computed tomography systems for the detection of vertical root fractures. J Endod 2010 Jan;36(1):126-129.

19. Kambungton J, Janhom A, Prapayasatok S, Pongsiriwet S. Assessment of vertical root fractures using three imaging modalities: cone beam CT, intraoral digital radiography and film. Dentomaxillofac Radiol 2012 Feb;41(2):91-95.

20. KhedmatS, RouhiN, DrageN,ShokouhinejadN,NekoofarMH. Evaluation of three imaging techniques for the detection of vertical root fractures in the absence and presence of guttapercha root fillings. Int Endod J 2012 Nov;45(11):1004-1009.

21. Youssefzadeh S, Gahleitner A, Dorffner R, Bernhart T, Kainberger FM. Dental vertical root fractures: value of CT in detection. Radiology 1999 Feb;210(2):545-549.

22. Iikubo M, Kobayashi K, Mishima A, Shimoda S, Daimaruya T, Igarashi $\mathrm{C}$, Imanaka $\mathrm{M}$, Yuasa $\mathrm{M}$, Sakamoto $\mathrm{M}$, Sasano $\mathrm{T}$. Accuracy of intraoral radiography, multidetector helical CT, and limited cone-beam CT for the detection of horizontal tooth root fracture. Oral Surg Oral Med Oral Pathol Oral Radiol Endod 2009 Nov;108(5):e70-e74.

23. Metska ME, Aartman IH, Wesselink PR, Özok AR. Detection of vertical root fractures in vivo in endodontically treated teeth by cone-beam computed tomography scans. J Endod 2012 Oct;38(10):1344-1347.

24. Kamburoglu K, Murat S, Yüksel SP, Cebeci AR, Horasan S. Detection of vertical root fracture using cone-beam computerized tomography: an in vitro assessment. Oral Surg Oral Med Oral Pathol Oral Radiol Endod 2010 Feb;109(2):e74-e81.

25. Patel S, Brady E, Wilson R, Brown J, Mannocci F. The detection of vertical root fractures in root filled teeth with periapical radiographs and CBCT scans. Int Endod J 2013 Dec;46(2):1140-1152. 